\title{
Thin-film dielectric elastomer sensors to measure the contraction force of smooth muscle cells
}

O. Araromi; A. Poulin; S. Rosset; M. Favre; M. Giazzon; C. Martin-Olmos; M. Liley; H. Shea

Proc. SPIE 9430, Electroactive Polymer Actuators and Devices (EAPAD) 2015, 94300Z (1 April 2015); doi: $\underline{10.1117 / 12.2083905}$

Copyright 2015 Society of Photo-Optical Instrumentation Engineers. One print or electronic copy may be made for personal use only. Systematic electronic or print reproduction and distribution, duplication of any material in this paper for a fee or for commercial purposes, or modification of the content of the paper are prohibited. 


\title{
Thin-film dielectric elastomer sensors to measure the contraction force of smooth muscle cells
}

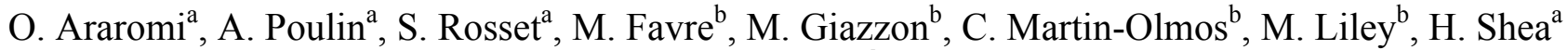 \\ ${ }^{\mathrm{a}}$ Microsystems For Space Technologies Laboratory, École Polytechnique Fédérale de Lausanne \\ (EPFL), CH-2000 Neuchâtel, Switzerland; \\ ${ }^{\mathrm{b}}$ Centre Suisse d'Electronique et de Microtechnique (CSEM), CH-2002 Neuchâtel, Switzerland
}

\begin{abstract}
The development of thin-film dielectric elastomer strain sensors for the characterization of smooth muscle cell (SMC) contraction is presented here. Smooth muscle disorders are an integral part of diseases such as asthma and emphysema. Analytical tools enabling the characterization of SMC function i.e. contractile force and strain, in a low-cost and highly parallelized manner are necessary for toxicology screening and for the development of new and more effective drugs. The main challenge with the design of such tools is the accurate measurement of the extremely low contractile cell forces expected as a result of SMC monolayer contraction (as low as $\sim 100 \mu \mathrm{N})$. Our approach utilizes ultrathin $(\sim 5 \mu \mathrm{m})$ and soft elastomer membranes patterned with elastomer-carbon composite electrodes, onto which the SMCs are cultured. The cell contraction induces an in-plane strain in the elastomer membrane, predicted to be in the order $1 \%$, which can be measured via the change in the membrane capacitance. The cell force can subsequently be deduced knowing the mechanical properties of the elastomer membrane. We discuss the materials and fabrication methods selected for our system and present preliminary results indicating their biocompatibility. We fabricate functional capacitive senor prototypes with good signal stability over the several hours ( $\sim 0.5 \%$ variation). We succeed in measuring in-plane strains of $1 \%$ with our fabricated devices with good repeatability and signal to noise ratio.
\end{abstract}

Keywords: Dielectric elastomer sensors, smooth muscle cells, strain sensing, force sensing, cell force phenotyping

\section{INTRODUCTION}

Smooth muscle disorders are an integral part of diseases such as asthma, chronic obstructive pulmonary disease and emphysema. Tools capable of characterizing cell function i.e. contractile force and strain, of both healthy and diseased smooth muscle cells (SMCs) are necessary for toxicology screening, and even development of new and more effective drugs.

Our approach, schematically represented in Figure 1, is the development of an array of low-cost, cell culture supports each with integrated cell force and strain measurement capabilities. In contrast to previously used techniques, which predominantly relied on optical methods ${ }^{[1]}$, our approach will read-out force and strain data electrically, allowing: a) high-throughput, parallel operation and scaling to a large number of culture wells $(>20)$, b) real-time measurement output, and c) use in a cell incubator. This will be achieved by using ultrathin $(\sim 5 \mu \mathrm{m})$ and soft $(\sim 0.1 \mathrm{MPa})$ elastomer membranes patterned with soft elastomer composite electrodes. A monolayer of SMCs patterned onto specific regions of the device contract in the presence of a chemical stimulus (Figure 1). This contraction induces strain in the device and this strain is measured via the change in the membrane capacitance (Figure 1). The contractile force can be deduced from the strain if the mechanical properties of the sensor are known i.e. the Young's modulus etc.

Electroactive Polymer Actuators and Devices (EAPAD) 2015, edited by Yoseph Bar-Cohen, Proc. of SPIE Vol. 9430, 94300Z · C 2015 SPIE · CCC code: 0277-786X/15/\$18 · doi: 10.1117/12.2083905 


\section{DEVICE REQUIREMENTS}

We outline the following general requirements for our sensing system in order of priority:

- Biocompatibility: the materials and methods used in device fabrication must not be toxic to the SMCs.

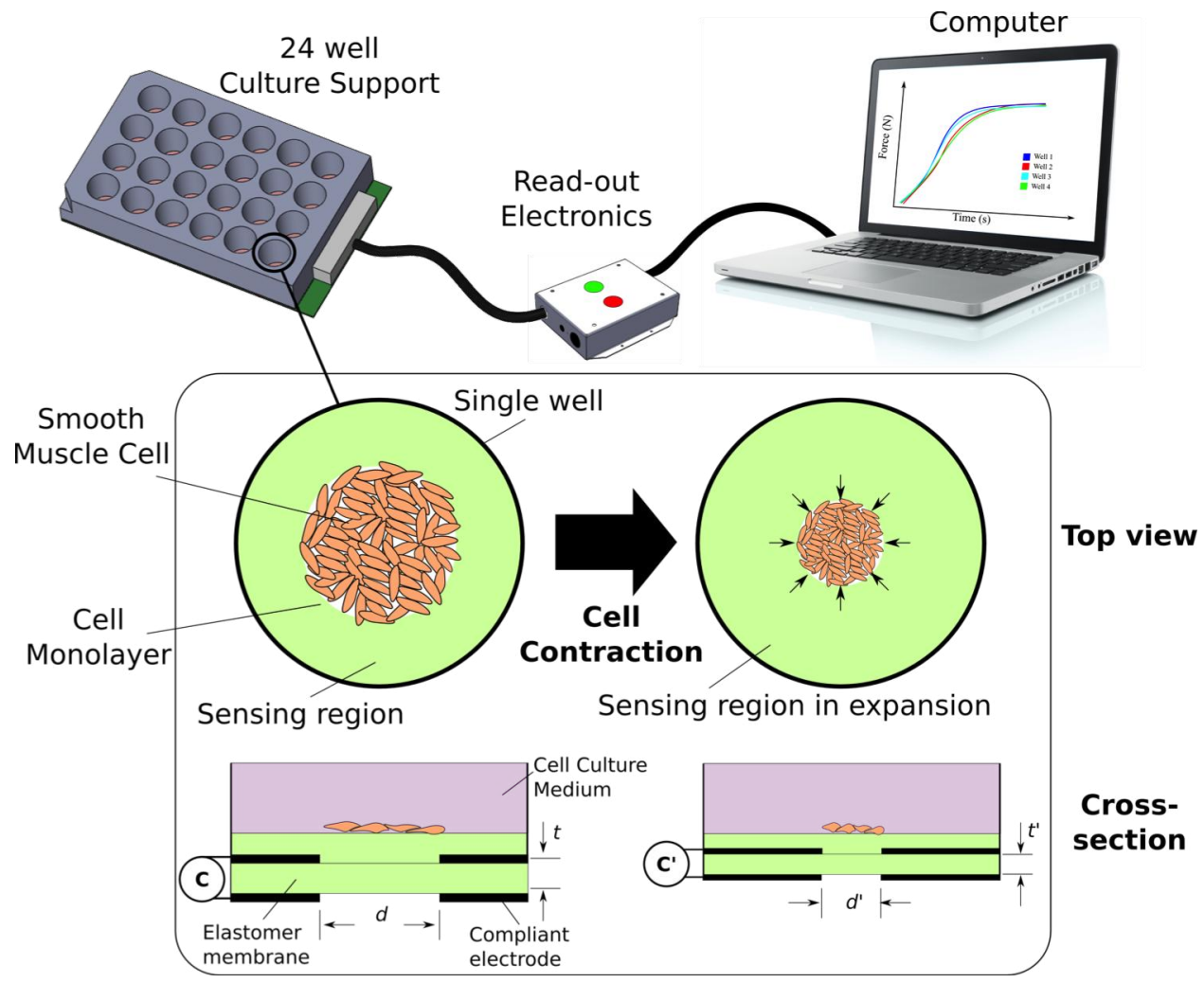

Figure 1. Schematic representation of proposed device. A 24-well cell culture support with integrated strain and force measurement with electrical read-out, allowing for high throughput parallel measurement in real-time (elastomer membrane shown in green, compliant electrodes shown in black). Cell contraction causes a change in the geometry of the sensor region i.e. cell region diameter goes from $d$ to $d^{\prime}$ ' and elastomer membrane thickness $t>t^{\prime}$. This in turn causes a change in device capacitance that can be measured. The contraction force can be deduced knowing the mechanical properties of the device. A passivation elastomer layer is included as this may be required to electrically isolate the device from the cells.

- High strain resolution: the stresses produced by a SMC (diameter approximately $10 \mu \mathrm{m}$ ) are of the order $10 \mathrm{kPa}^{[2]}$. Hence the force and the corresponding induced strain produced by the cell monolayer are likely to be very small. Therefore, a sensor with very good strain resolution is required.

- Signal stability: The device must be robust enough to function in a cell incubator i.e. at $37{ }^{\circ} \mathrm{C}, 0.5 \% \mathrm{CO}_{2}$ content and $>98 \%$ humidity. Additionally, initial characterization of cell behavior has shown that a cell contraction cycle (contraction and relaxation) can last up to two hours, hence a device must be able to function in a stable manner over a similar time period.

- Functioning in contact with liquid: the SMCs are grown in a liquid culture medium, therefore the device must be able to function whilst submerged or in contact with liquids ${ }^{[3]}$.

- Compatible with optical microscopy: initially we plan to use optical transmission microscopy to validate our sensor output, verifying that a cell contraction has actually taken place. Therefore it is desirable that device design allows the cells to be imaged in situ.

- Scalability: the fabrication methodology and sensing principle must be scalable to several wells $(>20)$ to enable parallel operation for high-throughput experimentation. The devices should be designed and fabricated in such a way as to ensure repeatable performance from one device to another. Moreover, device fabrication should not be too complex (for example requiring several fabrication steps) or expensive, which would inhibit scalability. 
- Ease of manipulation: the device should be robust enough to withstand the various fabrication and experimental steps, such as membrane prestretching, which is necessary to avoid buckling of the elastomer membranes during cell contraction, or the various washing steps involved in the sterilization procedure and cell culture.

Silicone elastomers, such as polydimethylsiloxane (PDMS), are often used in applications were biocompatibility is required $^{[4][5]}$. PDMS is also commercially available in variety of Young's moduli $\left(10^{2} \mathrm{kPa}-10^{2} \mathrm{MPa}\right)$ and can be cast into thin films using a variety of methods ${ }^{[6][7][8]}$, hence providing flexibility in design.

We select a capacitive sensing scheme for this work, were deformations in the elastomer dielectric are detected via the change in membrane capacitance (induced by the change in membrane geometry i.e. thickness reduction and surface area expansion (Figure 1)). Capacitive sensing is typically more insensitive to thermal variations and drift compared to other approaches (such as resistive sensing), ensuring signal stability ${ }^{[9]}$.

A simplified model was used to estimate the induced strain on a device as a function of the sensor thickness, Young's modulus of the elastomer membrane, cell contractile stress and device dimensions. Strains of up to $5 \%$ were predicted for cell contractile stresses in the range $1 \mathrm{kPa}-10 \mathrm{kPa}^{[2]}$ (equivalent to contractile forces in the range $2.0-0.2 \mathrm{mN}$ ), and membrane thickness as low as $10 \mu \mathrm{m}$ (including the electrodes).

\section{PROTOTYPE DEVELOPMENT}

\subsection{Elastomer membrane selection}

An evaluation of three soft silicone materials was conducted with the view of determining their feasibility for this work. The materials evaluated were: MED 4901 (NuSil) and Silbione LSR 4305 (Bluestar Silicones) silicone elastomers, and Sylgard 528 silicone gel (Dow Corning). The three materials were evaluated in terms of their ease of casting and handling (i.e. do they require special steps for rendering the material castable, special safety measures for working with the material, working time, etc.), surface quality of the cured films, ease of release from casting substrate and minimum casting thickness. All films were cast using a doctor-blade (or blade-casting) method using a Zehntner automatic film applicator, enabling fabrication of large area (several hundreds of $\mathrm{cm}^{2}$ ) membranes for eventual scaling up to a full sized $>20$ well device. Membranes were cast on to PET substrates coated with a poly(acrylic acid) (PAA) water-soluble sacrificial layer. The membranes were subsequently released by submersion in hot water. Pull tests were performed to determine the Young's modulus. The test specimen aspect ratio was 11:1 width to length relative to the pull direction, placing the specimen in a state of pure shear ${ }^{[9]}$. The Young's modulus was determined in the strain region $0-20 \%$.

The results of the characterization are summarized in Table 1 and show that the PDMS MED 4901 (NuSil) is an excellent candidate for this work. Membranes as thin as $3 \mu \mathrm{m}$ were successfully casted in a repeatable manner and with high yield. This was in part due to the high tear strength of this particular PDMS, being able to withstand strains over $1000 \%$ without tearing ${ }^{[11]}$. The membrane surface quality was also excellent (Figure 2), possessing good optical transparency. Additionally, even very thin membranes could be manipulated (for example, to apply a prestretch) after fabrication without causing rupture. By comparison, the silicon gel Sylgard 528, though having a lower Young's modulus, suffered frequent ruptures during handling or subsequent prestretching.

For the electrode, we use a silicone-carbon composite at a ratio of 10:1 by weight, using the same silicone selected for the sensing membrane (MED4901) as the elastomer matrix. Composite electrodes using the silicone gel Sylgard 528 were investigated but the presence of carbon severely inhibited cross-linking.

Cell growth tests were carried out on both the electrode and elastomer membrane material to give an indication of their toxicity to the cells. Human bronchial smooth muscle cells were cultured on top of the samples and were left for several days (Figure 3). The results show that cells survive even after being cultured for 7 days on the samples. 
Table 1. Characterization of soft silicone elastomers

\begin{tabular}{|c|c|c|c|}
\hline & $\begin{array}{c}\text { Silbione } 4305 \\
\text { (Bluestar Silicones) }\end{array}$ & $\begin{array}{c}\text { MED } 4901 \\
\text { (Nusil) }\end{array}$ & $\begin{array}{l}\text { Sylgard } 528 \\
\text { (Dow Corning) }\end{array}$ \\
\hline $\begin{array}{r}\text { Young's modulus, } \mathrm{MPa} \\
\text { (pure shear) }\end{array}$ & 0.23 & 0.13 & 0.1 \\
\hline $\begin{array}{r}\text { Solvent amount used in casting } \\
\text { (wt. \%) }\end{array}$ & 20 & $50-60$ & 0 \\
\hline Ease of release from substrate & Releases easily & Releases easily & $\begin{array}{c}\text { Releases but requires } \\
\text { care }\end{array}$ \\
\hline Surface quality/roughness & Good & Good & Good \\
\hline $\begin{array}{r}\text { Ease of handling cured } \\
\text { membrane }\end{array}$ & Good & Good & Poor \\
\hline
\end{tabular}
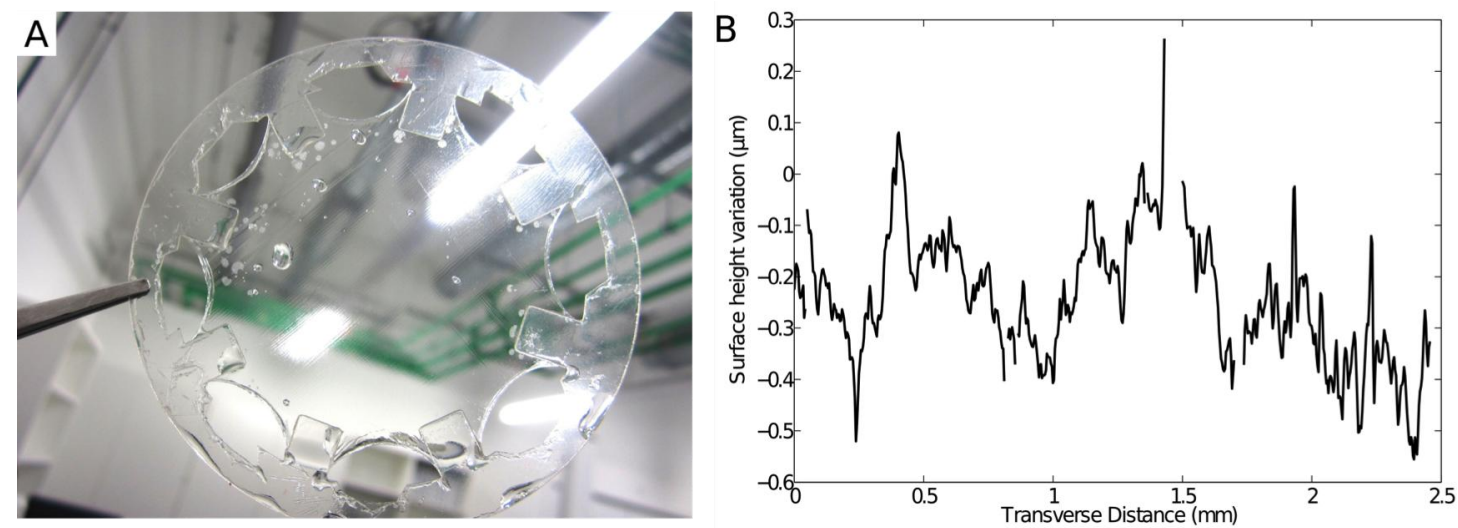

Figure 2. A) Example Free-standing $5 \mu \mathrm{m}$ thick MED-4901 silicone elastomer membrane. B) Surface height variation for a MED-4901 membrane sample of approximately $5 \mu \mathrm{m}$ thickness (gaps in data correspond to areas where dust particles had landed on the membrane).

\subsection{Patterning of electrodes on thin elastomer membranes}

Initially, an electrode patterning method based on pad printing (described in ${ }^{[12]}$ ) was investigated, where the pre-cured electrode composite is deposited onto the sensing elastomer membrane through a mask (laser cut with the desired electrode pattern) via a soft stamp. Tests were performed on $10 \mu \mathrm{m}$ thin MED4901 membranes prestretched biaxially by $20 \%$ with depositions applied using a Teca-print TPM101 pad-printing machine. This approach often led to rupture of the elastomer membrane due to the force of the stamp pressing on the mask (made from laser cut paper (Figure 4(A))). In our previous work we circumvented this issue by using masks coated with a soft silicone on the under-side ${ }^{[12]}$, however this was not possible in this case due to the high natural tack of the elastomer membrane, causing it to rupture when removing the mask.

An alternative to the pad printing method was developed in order to avoid excess stresses being imposed on the elastomer membrane (Figure 5). The method involves casting the electrode material on a PET substrate coated with PAA, in the same way as with elastomer membrane. After curing, the electrode design is etched using a laser cutter to the desired shape. The patterned electrode is subsequently bonded to the prestretched membrane using oxygen plasma treatment ${ }^{[13]}$. The treated surfaces of the electrode and elastomer membrane are brought into contact to initiate the bonding. The sacrificial layer was then dissolved in warm water. The method was later modified to use a poly vinyl 

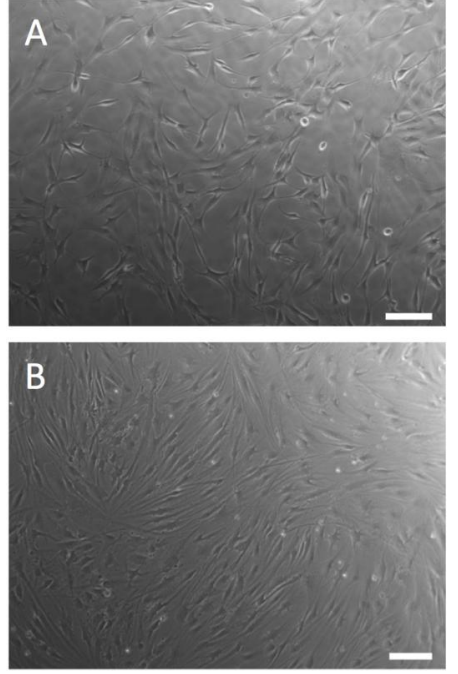
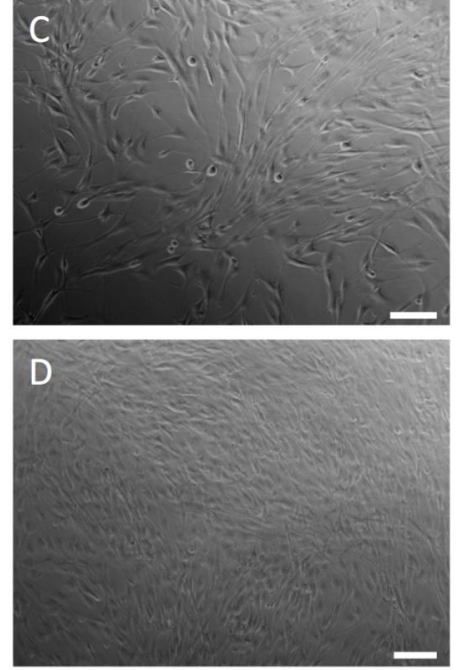

Figure 3. Bronchial smooth muscle cell growth toxicity tests for: MED-4901 silicone elastomer used for sensing membrane A) After 48 hours, B) after 7 days. Cell growth tests for compliant electrode material based on 10:1 wt. ratio of MED-4901 and carbon black (10:1 ratio by wt.); C) After 48 hours, D) After 7 days. (Scale bars $=200$ $\mu \mathrm{m}$.
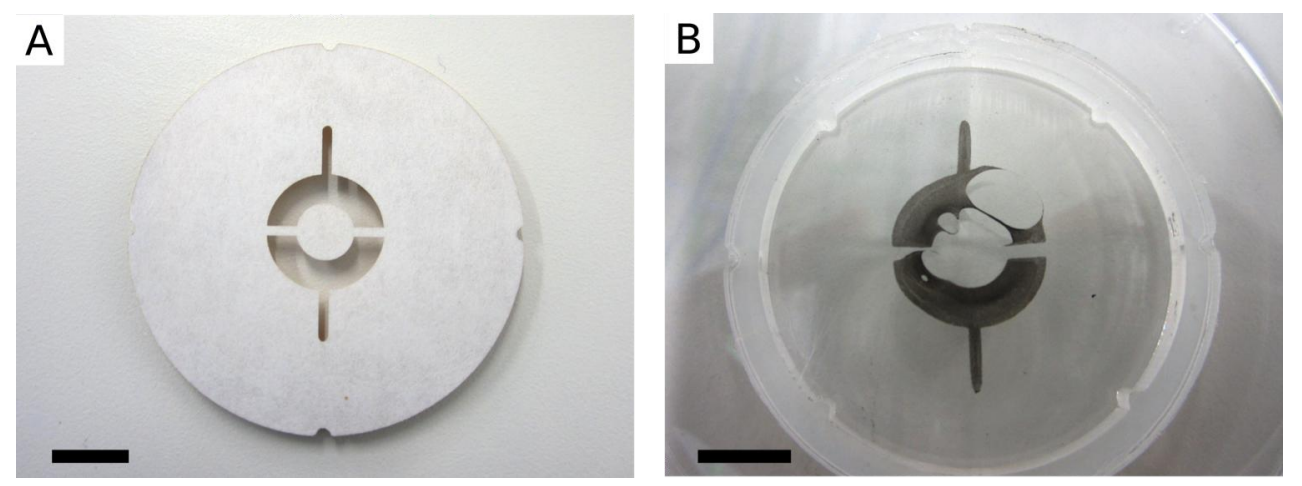

Figure 4. A) Laser cut paper pad-printer mask used to pattern thin elastomer membranes. B) Torn $5 \mu \mathrm{m}$ membrane as a result of stamp force applied via the stamp in the pad-printing process. Scale bars $=1 \mathrm{~cm}$.

alcohol (PVA) sacrificial layer in place of the PAA to prevent the PET bonding to the electrode due to the heat generated at the laser-cutting step. The affect of the plasma treatment on the elastomer membrane was characterized using a membrane inflation technique described $\mathrm{in}^{[14]}$. A stiffening effect of approximately $50 \%$ (relative Young's modulus increase) for a plasma exposure time of 11 seconds was observed but this effect may be reduced with shorter exposure times.

\section{DEVICE CHARACTERIZATION AND DISCUSSION}

A prototype sensor device was fabricated using the methodologies and materials outlined in section 3 and the signal stability over several hours was characterized (cell growth tests were conducted with PCB material and showed no toxicity to bronchial smooth muscles cells cultured on top). The geometry of the devices is shown in Figure 6(A). The electrode and elastomer membrane thicknesses were $7 \mu \mathrm{m}$ and $4 \mu \mathrm{m}$ (after a prestretch of $20 \%$ in each planar dimension), respectively and an exposure time of 11 seconds was used in the oxygen plasma bonding step. The imaginary part of the impedance (inversely proportional to the capacitance) was measured using an Agilent E4980 precision LCR meter at $300 \mathrm{~Hz}$ and the initial (no deflection) value was $-0.62 \mathrm{M} \Omega$ (equivalent to approximately $860 \mathrm{pF}$ assuming a series resistor-capacitor model). 


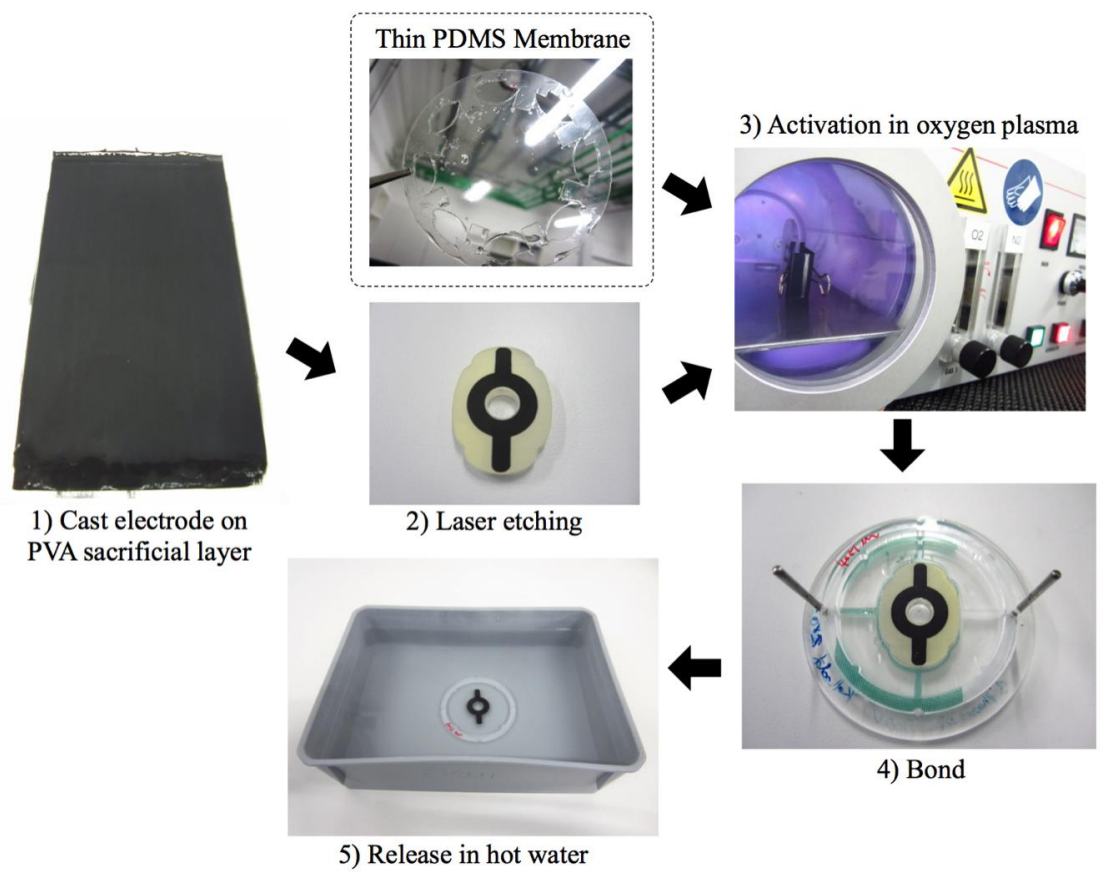

Figure 5. Electrode patterning method: 1) Cast electrode solution (MED-4901:carbon black at 10:1 wt. \%) onto a PET film coated with a water soluble sacrificial layer and cure. 2) Etch and cut desired electrode geometry by laser ablation. 3) Treat electrodes and casted thin MED-4901 membrane in oxygen plasma. 4) Place electrode in contact with membrane to achieve bonding. 5) Submerge in hot water to release electrode from PET substrate.

A $0.5 \%$ variation in the capacitance was observed for the sensor over a period of several hours, as shown in Figure 6 (b). A periodic noise could be observed which we assume to be the result of measurement frequency selected (a multiple of $50 \mathrm{~Hz}$ ) and electrical noise from the laboratory.

A test rig was developed to further characterize the signal in response to an out-of-plane deflection, generating in-plane strains in the range $1-2 \%$ in the sensing region (Figure 7(a)-(b)). A laser displacement sensor was used to validate the out-of-plane deflections produced using a manually operated linear stage. Cell growth medium also was placed on the under-side of the device during the test, partially simulating cell incubation conditions. The measrument frequency was $298 \mathrm{~Hz}$. The response of the device to the small induced strain is shown in Figure 7 (c), the sensor provided a very proportional response producing and relative change in the imaginary part of the impedance of $1 \%$. The response speed and repeatability were good, and the signal change could clearly be distinguished from the baseline noise.

\section{CONCLUSION}

Analytical tools capable of high-throughput parallel measurements of smooth muscle cell (SMC) contraction force are needed to more effectively tackle diseases associated with smooth muscle disorders. We propose the use of a multi-well array of cell culture supports, with integrated strain and force sensing capabilities using thin-film, dielectric elastomer sensors. We outline the requirements for our device and identify suitable materials and fabrication. The silicone elastomer MED-4901 (NuSil) showed excellent properties for this project, being able to be cast at thicknesses as low as 3 $\mu \mathrm{m}$ and being easily handled. Electrode patterning was accomplished using laser-patterned electrodes bonded to the elastomer membrane using oxygen plasma. In summary, a prototype device using a capacitive sensing methodology was fabricated showing good long-term signal stability over 14 hours with variations of $\sim 0.5 \%$. Preliminary biocompatibility tests have shown no signs of toxicity to the cells for the materials used in the prototype fabrication. Subsequent testing of the sensor prototype with an out-of-plane deflection (inducing in-plane strains of approximately 1\%, simulating cell contraction) produced a measureable signal change $(\sim 1 \%)$. The response was repeatable and could clearly be distinguished from the baseline noise. 

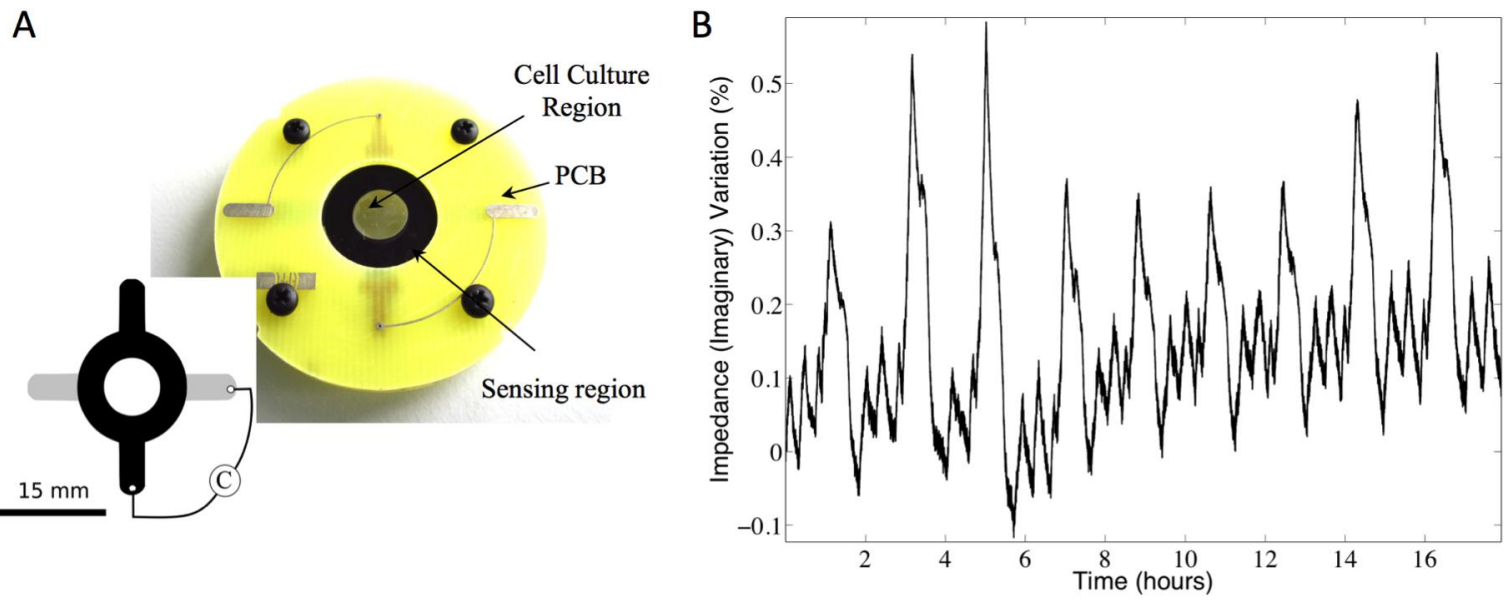

Figure 6. (a) Fabricated device with PCB interface, (b) Stability measurement: normalized sensor signal over a 14 hour period (initial impedance $=-0.6 \mathrm{M} \Omega$, equivalent to $860 \mathrm{pF}$ ).
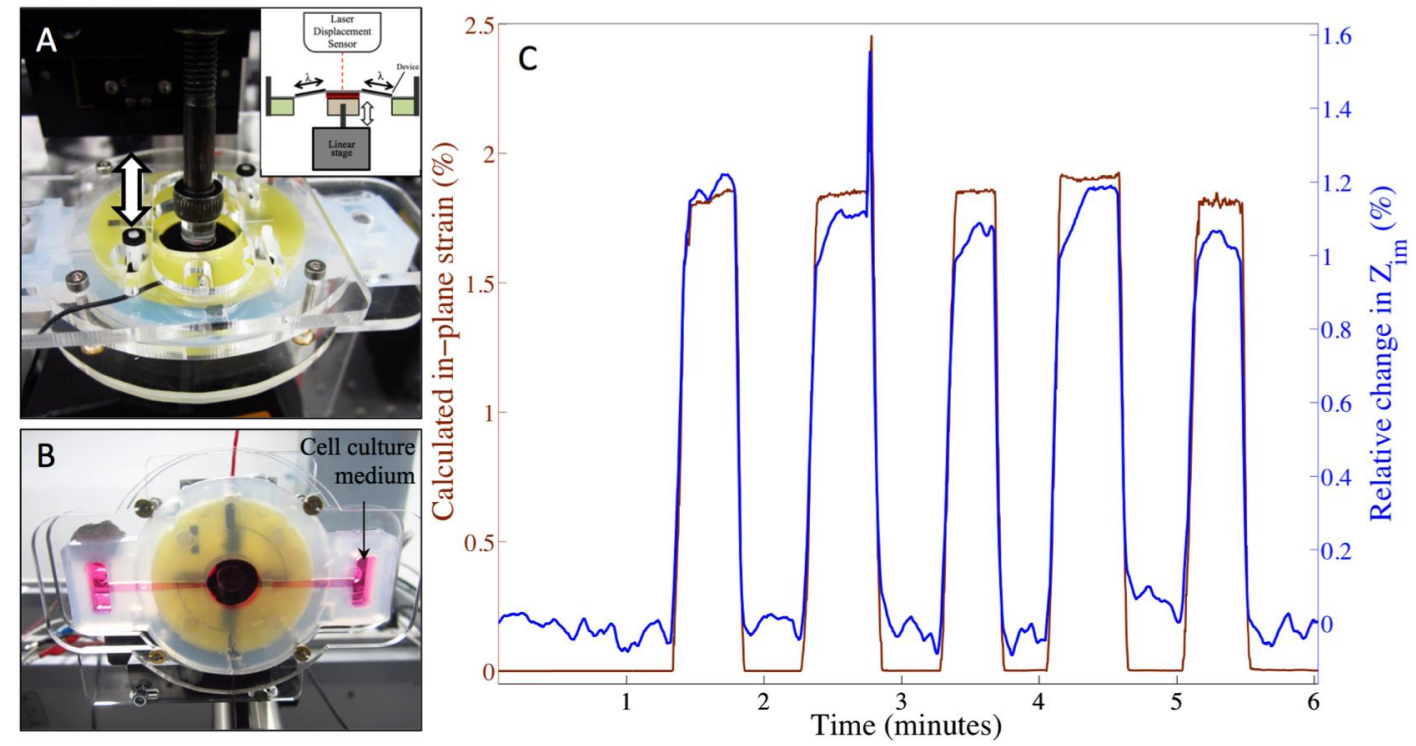

Figure 7. Characterization of capacitive sensor device: A) Experimental set-up for testing device response to out of plane deflection producing in-plane strains approximately equal to $1 \%$ (simulating cell contraction). B) Cell culture medium (purple liquid) in contact with device underside. C) Change in reactance (inversely proportion to capacitance) brought about by in-plane strains.

\section{ACKNOWLEDGMENTS}

This work was supported Nano-tera under NTF project Breathe, the Swiss National Science Foundation (SNSF) and EPFL. 


\section{REFERENCES}

[1] Grosberg, A., Alford, P. W., McCain, M. L.., Parker, K. K., "Ensembles of engineered cardiac tissues for physiological and pharmacological study: Heart on a chip," Lab Chip 11, 4165 (2011).

[2] Grosberg, A., Nesmith, A. P., Goss, J. A., Brigham, M. D., McCain, M. L.., Parker, K. K., "Muscle on a chip: In vitro contractility assays for smooth and striated muscle," J. Pharmacol. Toxicol. Methods 65, 126-135 (2012).

[3] Poulin, A., Maffli, L., Rosset, S., Shea, H., "Interfacing dielectric elastomer actuators with liquids," Proc. SPIE, paper 9430-35 (2015).

[4] Mata, A., Fleischman, A. J.., Roy, S., "Characterization of polydimethylsiloxane (PDMS) properties for biomedical micro/nanosystems.," Biomed. Microdevices 7, 281-293 (2005).

[5] Peterson, S. L., McDonald, A., Gourley, P. L.., Sasaki, D. Y., "Poly(dimethylsiloxane) thin films as biocompatible coatings for microfluidic devices: Cell culture and flow studies with glial cells," J. Biomed. Mater. Res. - Part A 72, 10-18 (2005).

[6] Araromi, O. A., Conn, A. T., Ling, C. S., Rossiter, J. M., Vaidyanathan, R.., Burgess, S. C., "Spray deposited multilayered dielectric elastomer actuators," Sensors Actuators A Phys. 167(2), 459-467, Elsevier B.V. (2011).

[7] Lotz, P., Matysek, M.., Schlaak, H. F., "Fabrication and Application of Miniaturized Dielectric Elastomer Stack Actuators," Mechatronics, IEEE/ASME Trans. 16(1), 58-66, IEEE (2011).

[8] Maffli, L., Rosset, S.., Shea, H. R., "Zipping dielectric elastomer actuators: characterization, design and modeling," Smart Mater. Struct. 22, 104013 (2013).

[9] Du, W. Y., "Capacitive Sensors," [Resistive, Capacitive, Inductive, and Magnetic Sensor Technologies], CRC Press, 99-152 (2014).

[10] Rosset, S., Araromi, O. a., Shintake, J., Shea, H. R., "Model and design of dielectric elastomer minimum energy structures," Smart Mater. Struct. 23, 085021 (2014).

[11] Nusil., "MED-4901 Liquid Silicone Rubber: Datasheet," 2013, <http://nusil.com/en/Product?id=MED$4901 \&$ catName=liquid silicone rubbers\&industry $=$ lifesciences \&segment $=$ generalhealthcare $>$.

[12] Araromi, S., Romano, P., Rosset, S., Perruisseau-Carrier, J.., Shea, H., "A tunable millimeter-wave phase shifter driven by dielectric elastomer actuators," Proc. SPIE 9056, 90562M (2014).

[13] Bhattacharya, S., Datta, a., Berg, J. M.., Gangopadhyay, S., "Studies on surface wettability of poly(dimethyl) siloxane (PDMS) and glass under oxygen-plasma treatment and correlation with bond strength," J. Microelectromechanical Syst. 14(3), 590-597 (2005).

[14] Rosset, S., Maffli, L., Houis, S.., Shea, H. R., “An instrument to obtain the correct biaxial hyperelastic parameters of silicones for accurate DEA modelling,” Proc. SPIE, 90560M-90560M (2014). 